\title{
The regulation and pharmacological modulation of immune complex induced type III IFN production by plasmacytoid dendritic cells
}

Karin Hjorton*, Niklas Hagberg, Pascal Pucholt, Maija-Leena Eloranta ${ }^{\dagger}$ and Lars Rönnblom ${ }^{\dagger}$

\begin{abstract}
Objective: Patients with systemic lupus erythematosus (SLE) have an ongoing interferon (IFN) production due to an activation of plasmacytoid dendritic cells (pDCs), which can be triggered to type I IFN synthesis by RNA containing immune complexes (RNA-IC). Considering emerging data suggesting a role of type III IFN in the SLE disease process, we asked if RNA-IC can induce type III IFN production in PDC and how this production can be regulated.
\end{abstract}

Methods: Peripheral blood mononuclear cells (PBMCs) or immune cell subsets were isolated from healthy blood donors or SLE patients and stimulated with IC containing U1 snRNP and SLE-IgG (RNA-IC). Hydroxychloroquine (HCQ) and an interleukin receptor 1-associated kinase 4 inhibitor (IRAK4i) were added to cell cultures. Cytokine mRNA levels were determined with a microarray and protein levels with immunoassays. Single-cell RNA sequencing of pDCs using ddSEQ technology was performed.

Results: Type III IFN mRNA and protein was induced in RNA-IC-stimulated pDC-NK and pDC-B cell co-cultures. A subset of activated pDCs (3\%) expressed both type III and type I IFN mRNA. IFN- $\lambda 2$, IFN- $\alpha 2$ b, interleukin (IL)-3, IL-6, or granulocyte-macrophage colony-stimulating factor (GM-CSF) enhanced IFN- $\lambda 1 / 3$ production $2-5$-fold. HCQ and an IRAK4i blocked the RNA-IC-triggered IFN- $\lambda 1 / 3$ production $(p<0.01)$. IFN- $22 \mathrm{~b}$ and GM-CSF increased the proportion of SLE patients producing IFN- $\lambda 1 / 3$ in response to RNA-IC from 11 to $33 \%$.

Conclusions: Type III IFN production is triggered by RNA-IC in PDCs in a TLR-MyD88-dependent manner, enhanced by NK and B cells as well as several pro-inflammatory cytokines. These results support a contributing role for both type I and type III IFNs in SLE, which needs to be considered when targeting the IFN system in this disease.

Keywords: SLE, IFN, pDC, NK, HCQ, IRAK4

\footnotetext{
* Correspondence: karin.hjorton@medsci.uu.se

${ }^{\dagger}$ Maija-Leena Eloranta and Lars Rönnblom shared senior authorship.

Department of Medical Sciences, Rheumatology, Science for Life Laboratory, Uppsala University, Rudbecklaboratoriet, Dag Hammarskjölds v 20, C11, 751 85 Uppsala, Sweden
}

(c) The Author(s). 2020 Open Access This article is licensed under a Creative Commons Attribution 4.0 International License, which permits use, sharing, adaptation, distribution and reproduction in any medium or format, as long as you give appropriate credit to the original author(s) and the source, provide a link to the Creative Commons licence, and indicate if changes were made. The images or other third party material in this article are included in the article's Creative Commons licence, unless indicated otherwise in a credit line to the material. If material is not included in the article's Creative Commons licence and your intended use is not permitted by statutory regulation or exceeds the permitted use, you will need to obtain permission directly from the copyright holder. To view a copy of this licence, visit http://creativecommons.org/licenses/by/4.0/ The Creative Commons Public Domain Dedication waiver (http://creativecommons.org/publicdomain/zero/1.0/) applies to the data made available in this article, unless otherwise stated in a credit line to the data. 


\section{Background}

Systemic lupus erythematosus (SLE) is a systemic autoimmune disease characterized by the presence of autoantibodies and immune complex (IC) formation. Via Toll-like receptors (TLRs), ICs can trigger the activation of the interferon (IFN) system, an important feature of SLE $[1,2]$. Hydroxychloroquine (HCQ), which interferes with endosomal TLR signaling, is the standard of care drug. A majority of SLE patients display an increased expression of IFN-regulated genes, an IFN signature, which contributes to the activation of immune cells, a sustained immune reaction, and several disease manifestations $[3,4]$. The IFN system consists of three classes of proteins, IFN types I-III, with antiviral and immunomodulatory properties, acting on separate receptors with different expression profiles [5]. Type I IFNs are mainly responsible for the IFN signature, but both type II and type III IFNs can be measured in a proportion of SLE patients and could contribute to the IFN signature [6]. Despite this, the exact role of type III IFNs in the generation of the IFN signature and thus in the SLE disease process is, to a large extent, unknown.

The type III IFNs, which include IFN- $\lambda 1-3$, or interleukin (IL)-29, IL-28A, IL-28B, respectively, and IFN- $\lambda 4$, are the most recently discovered IFNs. Type III IFN signals via the heterodimeric IFN- $\lambda$ receptor (IFNLR), and in contrast to the ubiquitously expressed IFN- $\alpha$ receptor (IFNAR), the IFNLR has a restricted expression, primarily to epithelial cells [7-9]. However, plasmacytoid dendritic cells (pDCs) as well as B cells, monocytes, and hepatocytes also express the IFNLR and can be targeted by IFN- $\lambda[10]$. Despite distinct receptors and different receptor expression patterns, type III and type I IFNs share a common downstream signaling pathway, including activation of STAT1-3 and IRF9 (ISGF3) recruitment. The gene expression induced by type III IFN is more limited than, but completely overlapping with, the type I IFN-stimulated genes $[11,12]$.

IFN- $\lambda$ is produced by pDCs, antigen-presenting cells (APCs), and epithelial cells in response to viruses, bacteria, and fungi, through activation of TLRs and cytosolic DNA sensors $[10,13,14]$. Once activated, pDCs mainly produce type I IFNs, but previous studies have demonstrated that herpes simplex virus (HSV) induces IFN- $\lambda$ production within a small subpopulation of the IFN- $\alpha$ producing pDCs [15].

One trigger of IFN- $\alpha$ production by $\mathrm{pDCs}$ in SLE is RNA or DNA containing IC, which via FcyRIIAmediated internalization activate TLRs 7 or 9, respectively [16]. Furthermore, interaction of pDCs with other cell types affects their cytokine producing capacity, as illustrated by the enhanced cytokine synthesis by TLRactivated pDCs co-cultured with NK cells [17-19], which can be suppressed by monocytes from healthy individuals [18]. $\mathrm{B}$ and $\mathrm{T}$ cells also increase the IFN- $\alpha$ producing capacity of pDCs [20, 21]. Based on these findings, our group has developed a model for pDC activation in SLE, using RNA-IC as an inducer of type I IFN and other pro-inflammatory cytokines [22].

In the present study, we asked if RNA containing ICs (RNA-ICs) have the capacity to induce type III IFN production in pDCs from healthy blood donors and whether this production is confined to a subset of pDCs. Furthermore, we studied the influence of other pro-inflammatory cytokines on the type III IFN response, and if TLR inhibition, through the antimalarial drug hydroxychloroquine (HCQ) or an interleukin-1 receptor-associated kinase 4 inhibitor (IRAK4i), modifies the production of type III IFN. We finally investigated if immune cells from SLE patients produced type III IFN in reponse to RNA-IC exposure.

\section{Materials and methods \\ Cell isolation and culture conditions}

Peripheral blood mononuclear cells (PBMCs) were prepared by Ficoll-Hypaque (GE-Healthcare) density-gradient centrifugation of buffy coats from healthy blood donors (Dept. of Transfusion Medicine, Uppsala University Hospital) or of EDTA blood from SLE patients and their healthy controls. CD14-depleted PBMCs, pDCs, NK cells, and $\mathrm{B}$ cells were isolated from PBMCs by negative selection, using CD14 MicroBeads, pDC isolation kit II, NK Cell Isolation Kit, and B cell isolation kit II, respectively (Miltenyi Biotec). The cell purity was $>95 \%$ and viability 92-98\% as determined by flow cytometry. CD14-depleted PBMCs $\left(400 \times 10^{3} /\right.$ well $)$, pDCs $\left(25 \times 10^{3} /\right.$ well $)$, NK cells $\left(50 \times 10^{3} /\right.$ well $)$, or B cells $\left(100 \times 10^{3} /\right.$ well $)$ were cultivated in a total volume of $100 \mu \mathrm{l} /$ well, in flat-bottomed 96-well plates (Nunclon) at $37^{\circ} \mathrm{C}$ with $5 \% \mathrm{CO}_{2}$ as described previously [18]. PDCs $\left(12.5 \times 10^{3} /\right.$ well $)$ and NK cells $\left(25 \times 10^{3} /\right.$ well) from SLE patients and their healthy controls were cultivated in a total volume of $50 \mu \mathrm{l} /$ well in $\mathrm{V}$-bottomed 96-well plates (Nunclon) [23]. When indicated, the cultures were supplemented with the following human recombinant cytokines: IL-3 (BioLegend), IL-6 (Roche), GM-CSF; Leukine (Beslex), IL-29, and IL-28A (Peprotech), IL-28B (Gibco), or IFN- $\alpha 2 b$ (IntronA; Schering Plough).

\section{Interferon inducers}

IgG was isolated from 2 SLE patient sera containing autoantibodies to Sm and RNP by protein G chromatography [22]. The U1 snRNP particles [24-26], with a purity of minimum 90\%, and SLE-IgG (RNA-IC) were used at final concentrations of $2.5 \mu \mathrm{g} / \mathrm{ml}$ and $1 \mathrm{mg} / \mathrm{ml}$, respectively [18]. UV-inactivated herpes simplex virus type 1 (HSV) was used at a final concentration of $10 \%(\mathrm{v} / \mathrm{v})$. 


\section{Drugs}

The small molecule drug IRAK4i I92 (ND-2158, Nimbus Discovery) [27] and HCQ (Sigma-Aldrich) were pretitrated and used at final concentrations of $10 \mu \mathrm{M}$ and $5.8 \mu \mathrm{M}$ (pDCs and NK cells), or $10 \mu \mathrm{M}$ and $7.8 \mu \mathrm{M}$ (monocyte-depleted PBMCs), respectively. The cells were pre-incubated with $\mathrm{I} 92$ or HCQ for $30 \mathrm{~min}$ at $5 \%$ $\mathrm{CO}_{2}, 37^{\circ} \mathrm{C}$ before adding IFN-inducers [28].

\section{Immunoassays}

IFN- $\lambda 1 / 3$ was measured using an enzyme-linked immunosorbent assay (IL-29/IL28B DuoSet ELISA kit, $R \& D$ Systems). When priming with IFN- $\lambda 2$, the acquired IFN- $\lambda 1 / 3$ concentrations in cultures were adjusted, due to cross reactivity of the ELISA kit antibodies with IFN$\lambda 2$ [15]. This was done by subtracting the detected levels of IFN- $\lambda 1 / 3$ in the IFN- $\lambda 2$ supplemented medium, from the acquired levels in RNA-IC-stimulated and IFN- $\lambda 2$ supplemented cell cultures (see additional file 1). Concentrations of IFN- $\lambda 2$ were measured using IL-28A ELISA Kit (Abcam). IFN- $\alpha$ concentrations were measured by a dissociation-enhanced lanthanide fluoroimmunoassay (DELFIA), as previously described [29] (1 IU/ $\mathrm{ml}$ corresponds to $5-10 \mathrm{pg} / \mathrm{ml}$ ). All cytokine levels were determined after $20 \mathrm{~h}$ of cultivation.

\section{Gene expression microarray}

mRNA levels in RNA-IC- or medium-stimulated cells from two healthy individuals were determined using the Agilent Whole Human Genome Microarray. Briefly, RNA was isolated after $6 \mathrm{~h}$ (Nucleospin RNA II, Macherey-Nagel) from pDCs, B cells, NK cells, and cocultured pDC-NK or pDC-B cells. For further details, see additional file 2 .

\section{Single-cell RNA expression profiling}

PDCs from two healthy blood donors $\left(50 \times 10^{3}\right.$ cells/well $)$ were stimulated with RNA-IC together with IFN- $\alpha 2 b$ $(500 \mathrm{IU} / \mathrm{ml})$ and IL-3 $(1 \mathrm{ng} / \mathrm{ml})$. Cell purity was $>95 \%$ as determined by flow cytometry staining of BDCA2. After $6 \mathrm{~h}$, cells were pooled and washed with cold phosphatebuffered saline (PBS) and 0.1\% human serum albumin. Cells were encapsulated in droplets and analyzed using the $\mathrm{ddSEQ}^{\mathrm{tw}}$ Single-Cell Isolator (Biorad) [30]. For further details, see additional file 2 .

\section{Statistical analysis}

Differences between two groups were analyzed with Wilcoxon signed rank test (paired samples) or MannWhitney test. Friedman's test for multiple comparisons was used when analyzing differences between $\geq$ three groups (GraphPad Prism 8.0 software). $p$ values $\leq 0.05$ were considered significant, ${ }^{*}$ refers to $p<0.05,{ }^{* *} p<$ $0.01,{ }^{* * * *} p<0.001$, and ${ }^{* * * * * *} p<0.0001$.

\section{Patients}

All 23 patients fulfilled $\geq 4$ of the 1982 American College of Rheumatology classification criteria for SLE [31]. Patients were 51 years old (median, range 32-81), with disease duration of 17.5 years (median, range 1-46). Disease activity was determined at the time of blood sampling using the SLEDAI-2 K [32]. Ten patients had a SLEDAI score between 1 and 10 whereas thirteen patients had SLEDAI score 0 (additional file 3). The local ethics committee approved the study protocol, and informed consent was obtained from all patients and controls.

\section{Results}

Type III IFN is induced in co-cultures of pDCs and NK cells or B cells stimulated with RNA-IC

To clarify if RNA-ICs trigger the expression of type III IFN in immune cells from healthy blood donors, we performed a microarray analysis of RNA-IC-stimulated pDCs, NK cells, or B cells, as well as pDC-NK or pDC-B cell co-cultures. As can be seen in Fig. 1a, the cocultures distinctly upregulated type III IFN mRNA in response to RNA-IC stimulation, more prominently in the pDC-NK co-cultures ( $>200$-fold) than in the pDC-B cells ( $>15$-fold). No relative increase in the expression of type III IFN genes was observed in RNA-IC-stimulated vs unstimulated pure pDC, NK, or B cell cultures. As expected, type I IFN was upregulated in RNA-ICstimulated pure $\mathrm{pDC}$ cultures in addition to the pDCNK or pDC-B co-cultures and type II IFN in NK and pDC-NK cell co-cultures. The pattern of substantial upregulation of gene expression in the co-cultures of pDCNK or B cells was also noted for some other RNA-ICinduced pro-inflammatory cytokine genes, such as IL12A and IL1F9 (IL-36) (Fig. 1b).

To determine if the increase in type III IFN mRNA expression corresponded with protein synthesis, cytokine levels in supernatants were quantified. As shown in Fig. 1c, d, RNA-IC induced no or low amounts of type III IFN in pDCs (IFN- $\lambda 2$; median $0 \mathrm{pg} / \mathrm{ml}$, range $0-13 \mathrm{pg} / \mathrm{ml}$, IFN$\lambda 1 / 3$; median $86 \mathrm{pg} / \mathrm{ml}$, range $0-354 \mathrm{pg} / \mathrm{ml}$ ) and NK cells (median and range $0 \mathrm{pg} / \mathrm{ml}$ ), whereas the levels were much higher in the pDC-NK cell co-cultures (median 103 $\mathrm{pg} / \mathrm{ml}$, range $15-357 \mathrm{pg} / \mathrm{ml}$, and median $1988 \mathrm{pg} / \mathrm{ml}$, range $377-6720 \mathrm{pg} / \mathrm{ml}$, for IFN- $\lambda 2$ and IFN- $\lambda 1 / 3$, respectively). Also in $\mathrm{pDC}-\mathrm{B}$ cell co-cultures, IFN- $\lambda 1 / 3$ levels were elevated compared to pure pDCs (additional file 4). Observing a more prominent increase in the type III IFN expression by pDC-NK cells compared to pDC-B cell cocultures, we proceeded to focus on the co-cultures of pDCs and NK cells. Furthermore, and in line with the microarray data, IFN- $\alpha$ levels in the pDC-NK and pDC-B cell co-cultures were significantly elevated compared to pure $\mathrm{pDC}$ cultures (additional file 5). 


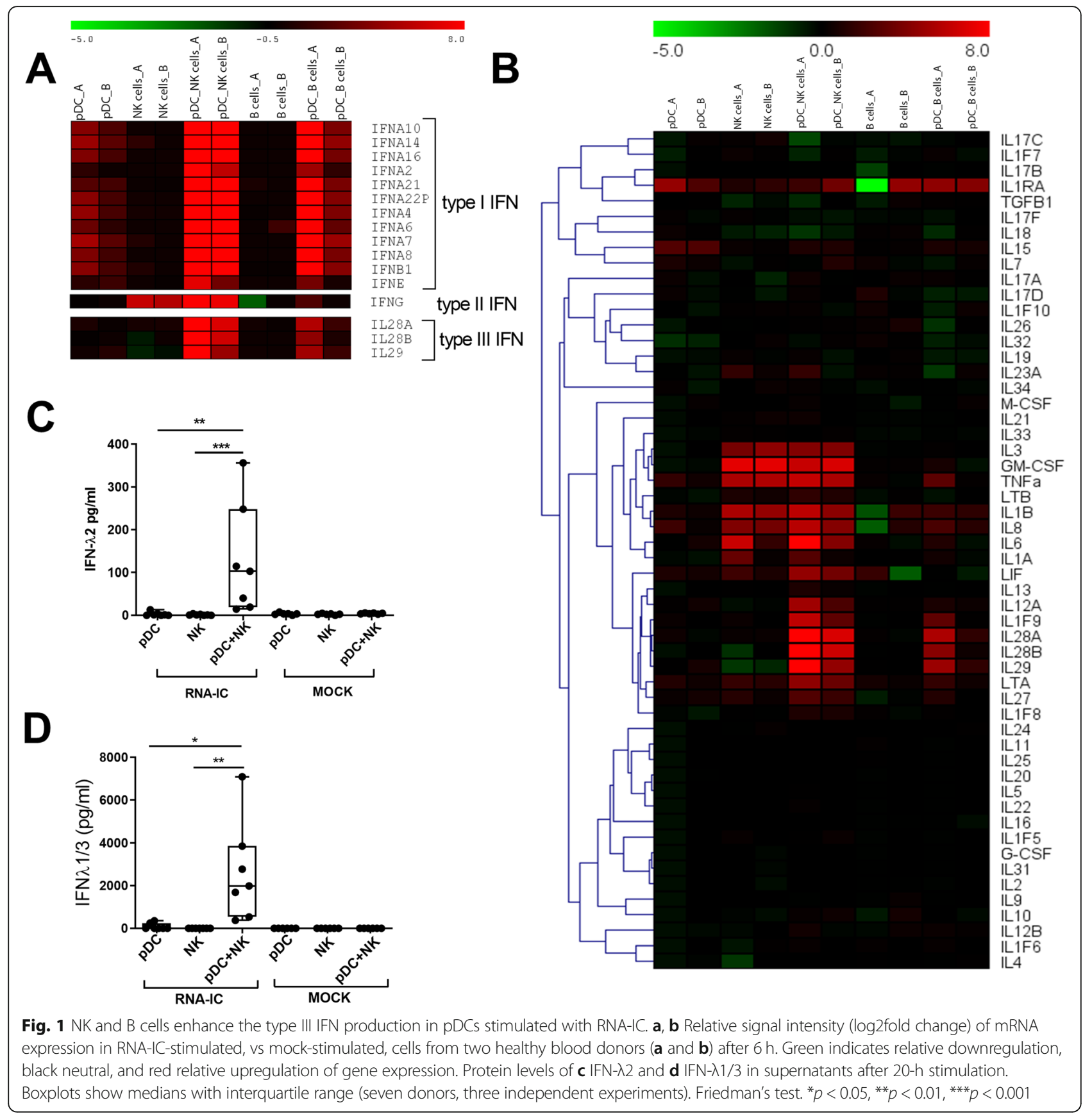

Thus, IFNs are produced in response to RNA-IC, and type I and III IFN production is increased by cocultivation of pDCs with NK cells or B cells.

Type III IFN and type I IFN promote the production of type III IFN

Next, we asked if type III IFN itself can enhance the IFN$\lambda 1 / 3$ production by RNA-IC-stimulated healthy blood donor pDCs, similar to the stimulating effect of type I IFN on the IFN- $\alpha$ production by pDCs, also termed priming $[18,33]$. Furthermore, we asked if IFN- $\alpha$ exerts a priming effect on IFN- $\lambda$ production. Figure $2 \mathrm{a}$ shows that IFN- $\lambda 2$ exhibits a significant priming effect on IFN- $\lambda 1 / 3$ production with a maximum 5 -fold increase, whereas a 2 -fold priming effect by IFN- $\alpha 2$ b was observed (Fig. $2 b$ ).

Given the priming effect by IFN- $\lambda 2$, we investigated if the RNA-IC-induced type III IFN synthesis by pDCs can be enhanced by other cytokines besides the type I and III IFNs. As seen in Fig. $2 \mathrm{c}-\mathrm{e}$, the IFN- $\lambda 1 / 3$ production by RNA-IC-stimulated pDCs was significantly enhanced already at $0.1 \mathrm{ng} / \mathrm{ml}$ by IL-3 and GM-CSF and at $1 \mathrm{ng} / \mathrm{ml}$ by IL- 6 to maximum 4-fold levels. Likewise, IFN- $\alpha$ 


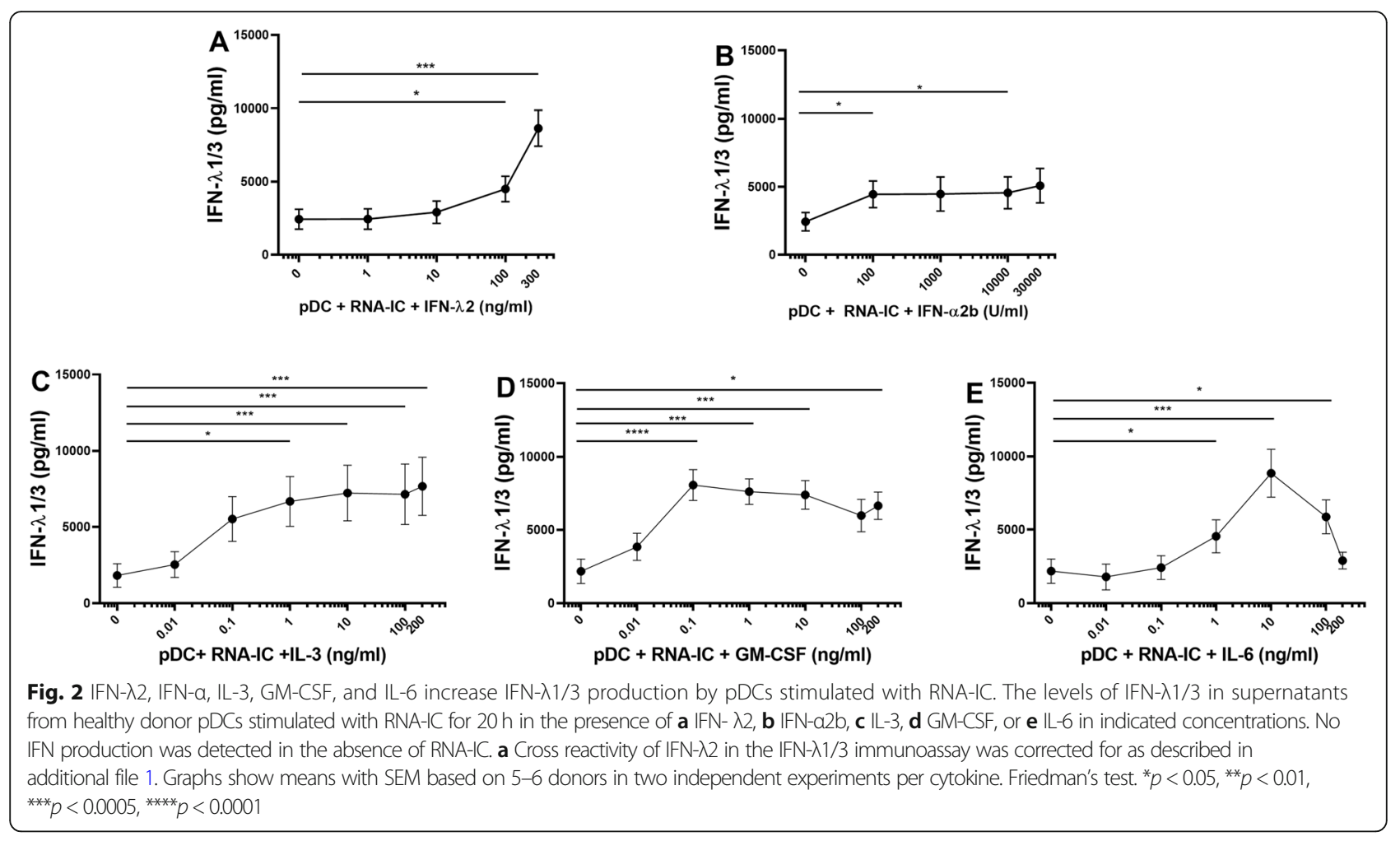

production was enhanced by IL-3, GM-CSF, and IL-6 (additional file 6). Levels of RNA-IC-induced IFN- $\alpha$ were $30-40$ fold higher than corresponding IFN- $\lambda 1 / 3-$ levels, and the relative increase in IFN- $\alpha$ was greater than that in IFN- $\lambda 1 / 3$ (8-10-fold).

We also investigated whether type III IFNs affected the RNA-IC-stimulated IFN- $\alpha$ production by pDCs. Figure 3 shows that IFNs- $\lambda 1-3$ increased the IFN- $\alpha$ levels to maximum 2-fold at a concentration interval of $10-100 \mathrm{ng} / \mathrm{ml}$. IL-1 $\beta$, MIP-1 $\beta$, and TNF- $\alpha$ added to cell cultures at concentrations $0-10 \mathrm{ng} / \mathrm{ml}$ did not affect the RNA-ICinduced IFN- $\lambda 1 / 3$ or IFN- $\alpha$ production (data not shown).

In summary, both type III and type I IFNs as well as IL-3, IL-6, and GM-CSF enhance the production of type
III and type I IFNs by RNA-IC-stimulated pDCs. The pDCs display a more pronounced IFN type I than type III response to RNA-IC stimulation and to priming.

\section{A small subset of pDCs produce both type I and type III IFNs in response to RNA-IC}

To clarify if different subclasses of pDCs account for the production of type I and type III IFNs, pDCs from healthy blood donors were stimulated with RNA-IC and singlecell RNA sequencing was performed. Unsupervised clustering using the 2000 most variable genes identified two distinct clusters of pDCs (Fig. 4a), of which the minor subset, cluster $1(3.2 \%)$, was essentially characterized by IFN gene activation (Fig. 4b). In total, 164 differentially
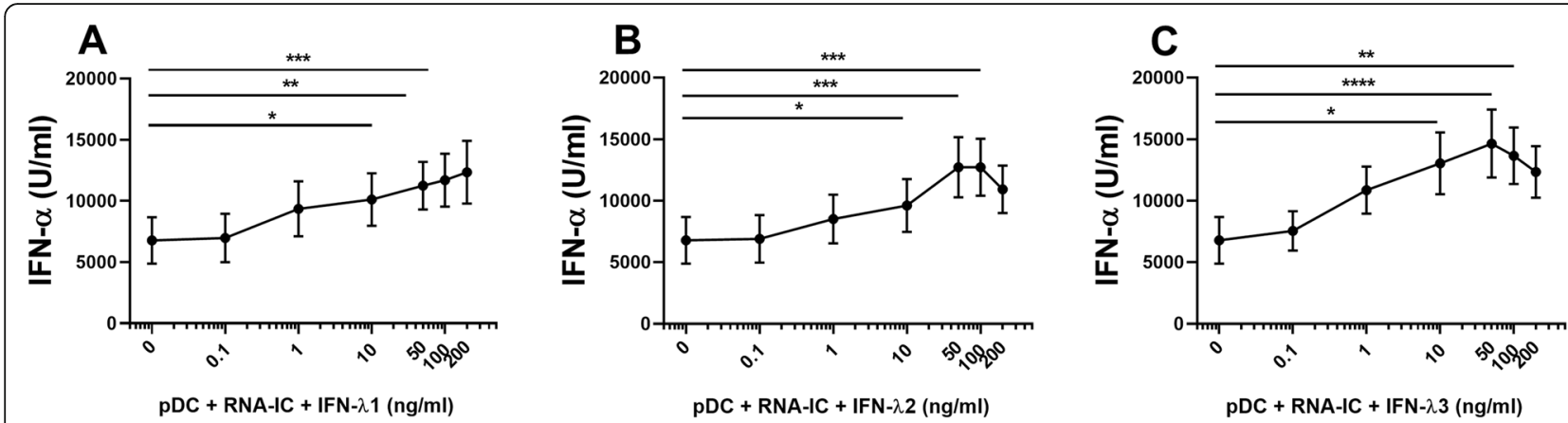

Fig. 3 Type III IFNs increase IFN-a production by pDCs stimulated with RNA-IC. The levels of IFN-a in supernatants from healthy donor pDCs stimulated with RNA-IC for $20 \mathrm{~h}$ in the presence of $\mathbf{a}$ IFN- $\lambda 1$, $\mathbf{b}$ IFN- $\lambda 2$, or $\mathbf{c}$ IFN- $\lambda 3$ at indicated concentrations. No IFN production was detected in the absence of RNA-IC. Graphs show means with SEM based on six donors in two independent experiments. Friedman's test. ${ }^{*} p<0.05$, ${ }^{* *} p<0.01$, ${ }^{* * *} p<0.001$ 


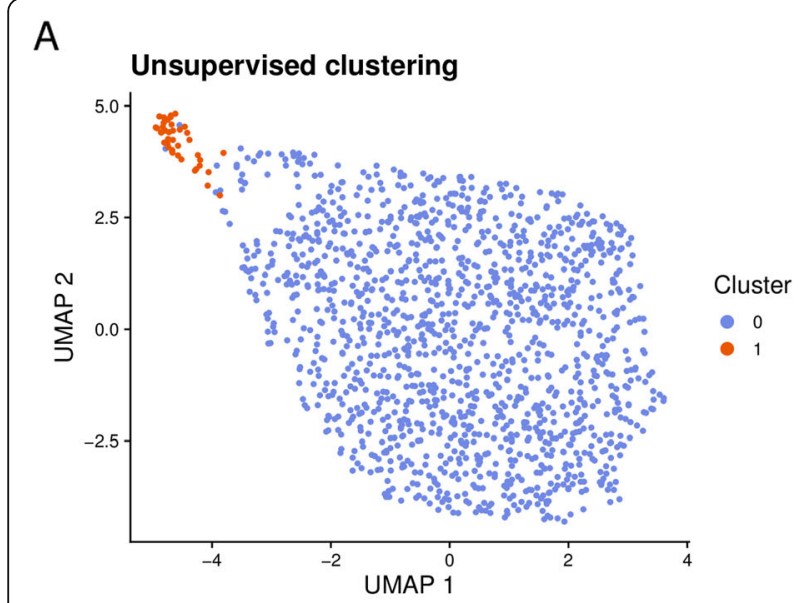

\section{B}

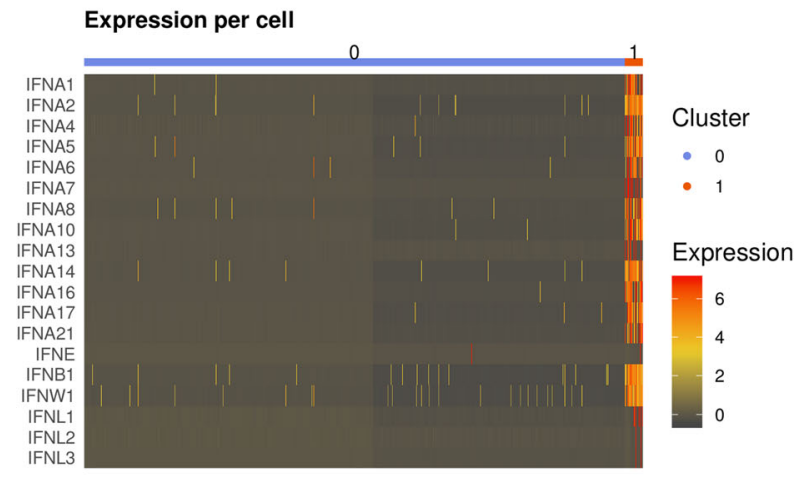

C
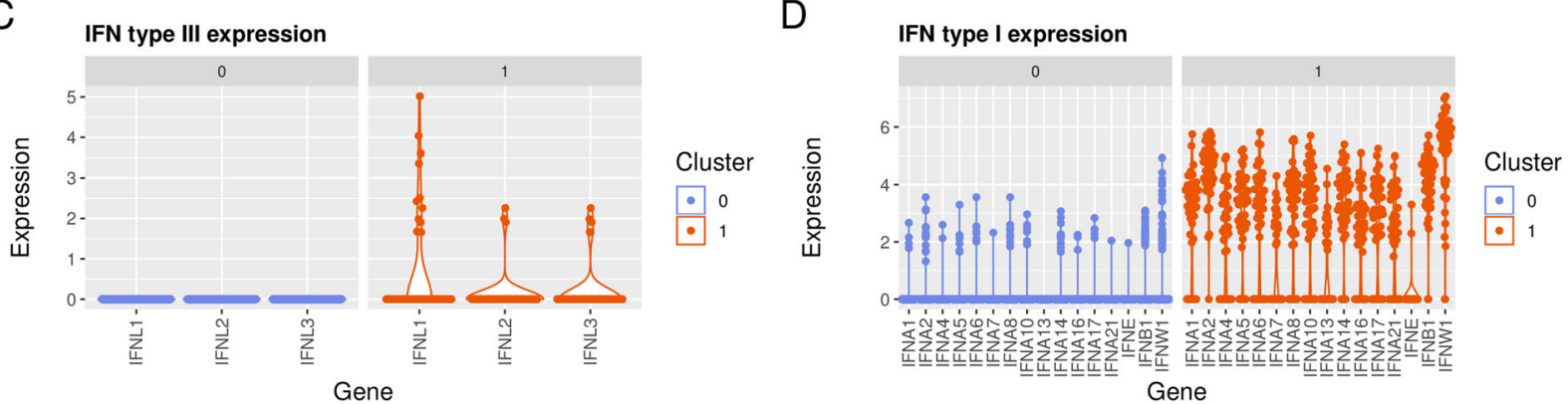

Fig. 4 Type I and type III IFN expression in pDCs on the single-cell level. a Results from single-cell RNA sequencing illustrated by unsupervised clustering of 1413 healthy blood donor $(n=2)$ pDCs by non-linear two-dimensional Uniform Manifold Approximation and Projection (UMAP) embedding. Cells were stimulated with RNA-IC, IL-3, and IFN-a2b. Cluster " 0 " (blue) and cluster "1" (orange). b IFN gene expression per cell for cluster "0" and "1". Individual cell expression levels of subtypes of $\mathbf{c}$ type III IFNs, and $\mathbf{d}$ type I IFNs, within clusters "1" and "0". The cell purity was $>95 \%$ as determined by flow cytometry staining of BDCA2

expressed genes (DEGs) (adjusted $p$ value $<0.05)$ were identified between the clusters. Type III IFN, dominated by IFN- $\lambda 1$, was exclusively expressed in cluster 1 (Fig. 4c). Moreover, type I IFN genes were induced in the majority of cells in cluster 1 and at higher levels compared to cluster 0 , where a minority of cells expressed low levels of type I IFNs (Fig. 4d). When comparing the most significantly differentially expressed genes between cluster 1 and cluster 0 (adjusted $p$ value $<1 \times 10^{-15}, n=54$ ), besides the IFN gene predominance in cluster 1 , a significant upregulation of other genes mapping to immune activation was found, such as cytokine and chemokine genes CCL4, CCL3, TNF, CCL3L3, and IL12A $(\log 2 \mathrm{FC}>1)$ as well as CD4O (additional file 7). In cluster 0 , on the other hand, 19 genes were overexpressed compared to cluster 1 (of which four exceeded $\log 2 \mathrm{FC}>1$, additional file 8). Among these, TLR7, STAT1, and OAS1 were noted, as well as several ribosomal protein genes.

Hence, a small minority of pDCs are responsible for the upregulated IFN gene expression upon RNA-IC stimulation, and type III IFN gene expression occurred within a subset of the type I IFN expressing pDC population.
Type III IFN production in RNA-IC-stimulated pDC and pDC-NK co-cultures is inhibited by an IRAK4 inhibitor and by hydroxychloroquine

Considering that IFN induction by RNA-IC is mediated through endosomal TLR binding, we asked if HCQ could inhibit this production. In RNA-IC-stimulated pDCs and NK cells from healthy blood donors, HCQ almost completely blocked the IFN- $\lambda 1 / 3$ production (Fig. 5). An IRAK4 inhibitor, which acts downstream of the endosomal TLRs, was equally effective in blocking the IFN- $\lambda 1 / 3$ production by the pDCs and $\mathrm{pDC}-\mathrm{NK}$ cell cultures.

Thus, RNA-IC-induced type III IFN production by pDCs and NK cells is inhibited by HCQ as well as by an IRAK4 inhibitor.

RNA-IC induces type III IFN production in immune cells from a subset of SLE patients, and GM-CSF and IFN-a2b increase the proportion of responders

We finally investigated cells from SLE patients and compared their IFN production with cells from healthy controls. In monocyte-depleted RNA-IC-stimulated PBMCs, IFN- $\lambda 1 / 3$ was detected in $15 \%(n=2)$ and $30 \%(n=3)$ of patients and controls, respectively (Fig. 6). In comparison, 


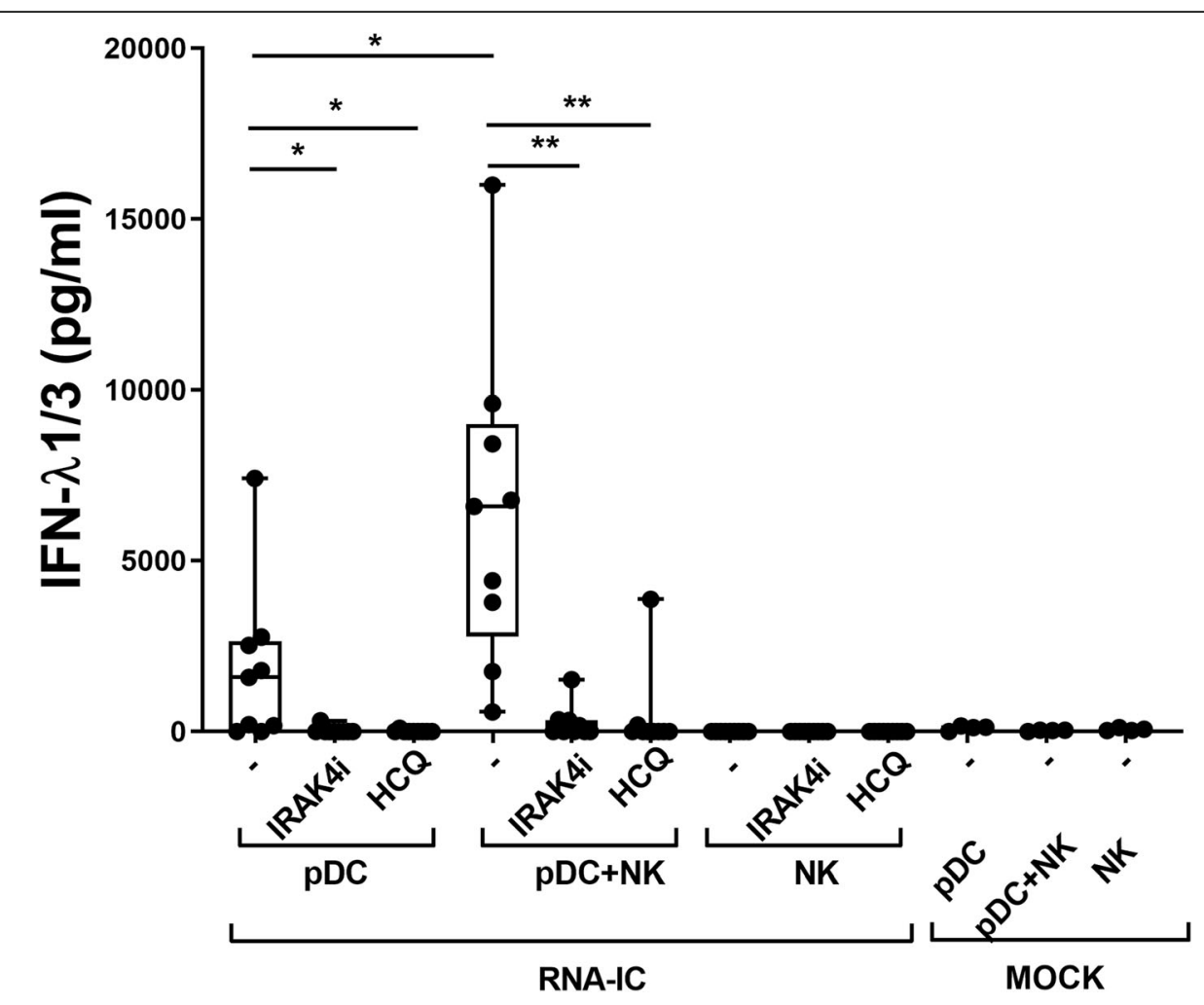

Fig. $5 \mathrm{IFN}-\lambda 1 / 3$ production by pDCs and pDC-NK cell co-cultures is inhibited by an IRAK4i and HCQ. The levels of IFN- $\lambda 1 / 3$ after $20 \mathrm{~h}$ in supernatants

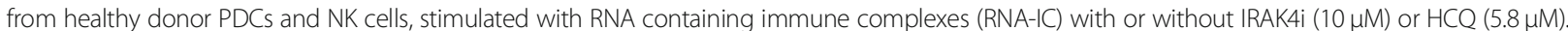
Boxplots show medians with interquartile range, based on nine donors in three independent experiments. Friedman's test. ${ }^{*} p<0.05$, ${ }^{* *} p<0.01$

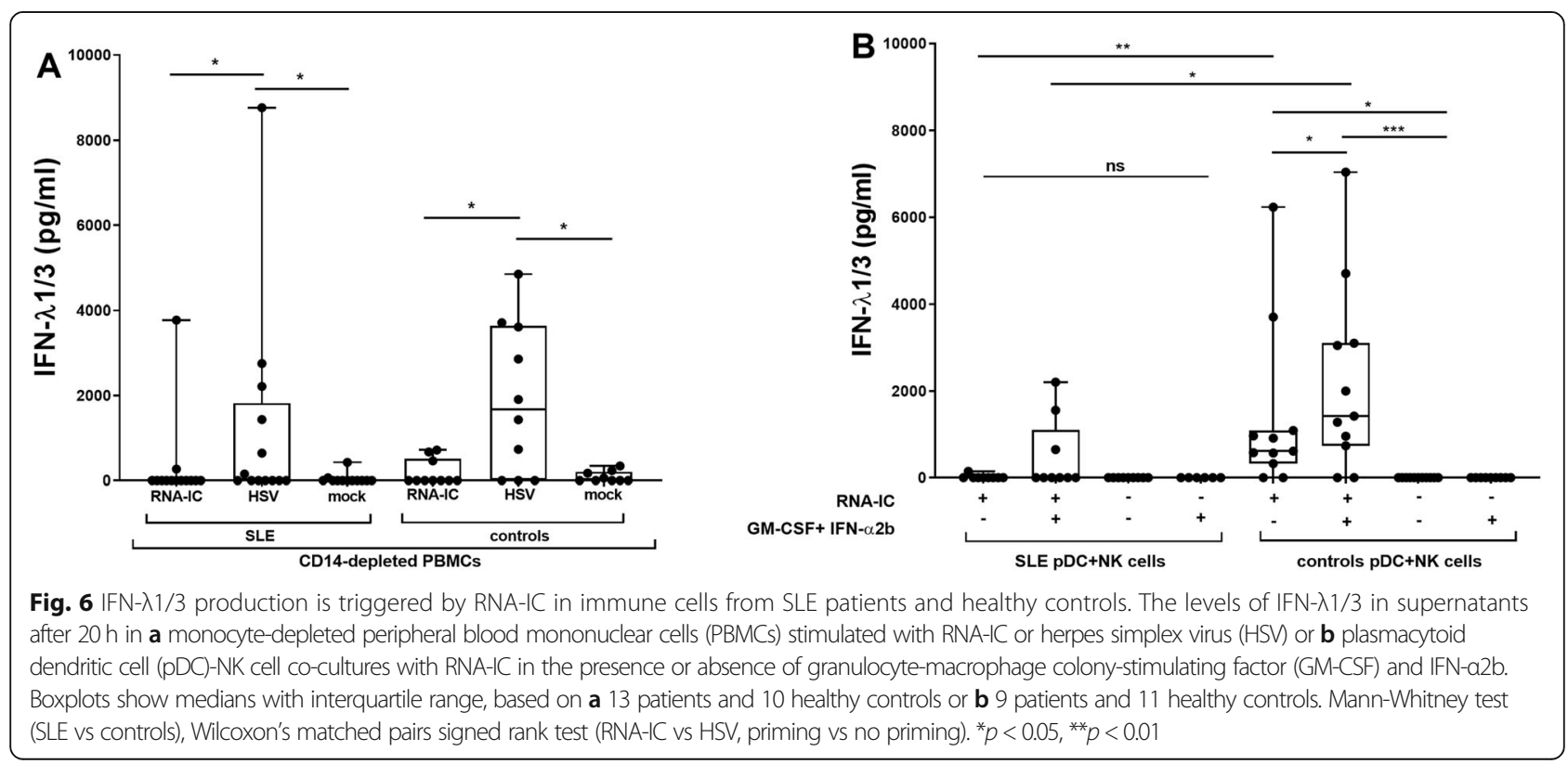


higher IFN- $\lambda 1 / 3$ levels and larger proportions of patients and controls producing IFN- $\lambda 1 / 3$ were observed in response to the TLR 9 agonist HSV1. In purified, RNA-ICstimulated, pDC and NK cell co-cultures from SLE patients, IFN- $\alpha 2 b$ and GM-CSF priming marginally increased the IFN- $\lambda 1 / 3$ levels (from means 14 to $455 \mathrm{pg} / \mathrm{ml}, p=0.125$ ) and the proportion of responders (from 11 to $33 \%, n=1-$ 3). RNA-IC-induced IFN- $\alpha$ levels were higher than IFN- $\lambda 1 /$ 3 levels and detected in a larger proportion of patients and controls (additional file 9). PDC-NK cell co-cultures from all IFN- $\lambda 1 / 3$ producing individuals responded to RNA-IC with IFN- $\alpha$ production. IFN production was lower in SLE patients than in healthy controls.

In conclusion, type III IFN production by monocytedepleted PBMCs and pDC-NK cell co-cultures can be induced by RNA containing IC, in a subset of SLE patients. A trend toward higher IFN- $\lambda 1 / 3$ levels, as well as higher numbers of RNA-IC responders, was observed after IFN- $\alpha 2 b / G M-C S F$ treatment.

\section{Discussion}

In this report, we show that nucleic acid containing ICs induce type III IFN expression and protein production in pDCs from healthy blood donors. Using single-cell RNA sequencing, we also show that type III IFN expression in response to RNA-IC occurs within the small $\mathrm{pDC}$ subset that produces type I IFN, which is in line with previous observations [15]. These findings connect the type I and type III IFN production in pDCs and suggest that similar mechanisms may be operative in pDCs for the production of both these cytokines. Furthermore, since RNA containing ICs are present in SLE and can activate pDCs, our observations could be relevant to the understanding of the observed presence of type III IFN in serum and tissues in a subset of SLE patients [18, 22, 34].

The significant increase of type III IFN production noted, when NK or B cells were added to healthy pDC cultures, shows that type III IFN synthesis can be regulated by other immune cells. This observation indicates that the type III IFN response is part of the cross talk between different immune cells in the presence of nucleic acid containing ICs, as in SLE. Such cell interactions have previously been shown to contribute to the type I IFN production by pDCs [1821]. The most powerful effect has been observed by NK cells, mainly mediated through cell-cell contact via lymphocyte function-associated antigen (LFA)-1 [19]. Herein, we also demonstrate that cytokines, previously shown to be increased in the serum or tissue of patients with SLE, strongly enhance the type III IFN production by healthy pDCs. These cytokines include IFN- $\alpha$ [35], GM-CSF [21, 36, 37], IL-6 [38, 39], and IL-3 [40-42], but also type III IFN itself [6, 43]. Furthermore, all type III IFN subtypes enhanced the
IFN- $\alpha$ production. Taken together, these observations indicate that type III IFNs could partake in the positive feed-forward loop seen in SLE and contribute to the vicious circle with an ongoing IFN production and sustained immune activation [44].

The impact of type III IFN on the IFN signature in SLE probably varies between patients, as only a proportion of patients responded to RNA-IC and the magnitude of the type III IFN production differs considerably between individuals. A great inter-individual variation of the IFN- $\alpha$ response has previously been described, its production being affected by a number of genes [45], and it is possible that genetic variation affects the type III IFN response as well. The selection of cells investigated for gene expression profile (i.e., the IFN signature) is also of importance, as the IFNLR receptor is expressed by a limited number of cell types $[8,10]$. The fact that pDCs displayed a more pronounced IFN type I than type III response to RNA-IC stimulation and to priming, however, supports the notion that type I IFN is more important for the IFN signature in SLE.

Both HCQ and an IRAK4 inhibitor blocked the type III IFN production by pDCs and NK cell co-cultures in response to RNA-IC stimulation. Thus, the production triggered via the TLR7-MyD88 signaling pathway can be inhibited by drugs targeting a pro-inflammatory route considered important in SLE. Whether HCQ or IRAK4 inhibition also can block type III IFN production in other cell types than pDCs remains to be determined. This is important, since expression of type III IFN to a large extent has been shown to occur at mucosal sites and in tissues, where it is produced by a number of different cell types. In fact, one major effect of type III IFNs is promoting the local immunity and preventing microbiologic invasions, rather than affecting systemic inflammation $[10$, 13]. Pursuing to block the potentially deleterious type III IFN production in SLE patients may therefore harbor certain risks, as it is conceivable that a complete inhibition may cause an increased propensity for infections, especially via the mucosal tissues. On the other hand, specifically blocking the type I IFN response may preserve the mucosal antiviral defense system, yet perhaps only partially ameliorate SLE disease manifestations [46].

There are several observations suggesting that type III IFN is of importance in SLE. Thus, IFN- $\lambda 1$ can be detected in SLE patients' blood as well as in lupus nephritis crescents and cutaneous lupus erythematosus (CLE) skin lesions [43, 47]. Serum levels of IFN$\lambda 1$ correlate with disease activity and specific organ manifestations, such as arthritis and nephritis, as well as the presence of antibodies to double-stranded DNA $[48,49]$. Furthermore, serum IFN- $\lambda 3$ levels have been associated with active mucocutaneous lupus 
disease [50]. Genetic polymorphisms in IFN- $\lambda 3 / 4$ have also been associated with lupus nephritis susceptibility, indicating a role for type III IFN in active SLE [49]. Given these observations, we proceeded to investigate if immune cells from patients with SLE can produce type III IFN.

We noted that RNA-ICs triggered IFN- $\lambda 1 / 3$ production in monocyte-depleted PBMCs from a minority of patients and the proportion of responding individuals was lower than in healthy controls. In the cocultivated purified pDCs and NK cells from SLE patients, only a small subset of patients responded to RNA-IC stimulation with type III IFN production. There are several possible reasons for this observation, for instance reduced IFN producing capacity of patients' pDCs, due to treatment, concurrent infections, or a refractory state following in vivo activation [51]. Furthermore, the amount of produced type III IFN was markedly lower than that of type I IFN, which perhaps is not surprising when considering that only a subset of the IFN- $\alpha$ expressing pDCs expressed IFN- $\lambda 1 / 3$ in the single-cell RNA seq. A modest priming effect by GM-CSF and IFN- $\alpha 2 b$ was observed, increasing the number of type III IFN producing individuals and the levels of type I IFN production in SLE patients. This may be of relevance for the in vivo situation in SLE with increased levels of several proinflammatory cytokines, as discussed above. However, large patient cohorts followed longitudinally are needed in order to clarify the connection in SLE between type III IFN production and disease activity, as well as the impact of HCQ treatment.

There are limitations to this study. When isolating subsets of immune cells from SLE patients, the availability of blood limits the experiment size and numbers. In addition, migration of pDCs to tissues makes it difficult to obtain a sizable number of these cells for more extensive experiments [52]. It also cannot be ruled out that the IFN- $\lambda 1 / 3$ response to RNA-IC in our samples is somewhat underestimated, due to the relatively high lower level of quantification (LLoQ $62.5 \mathrm{pg} / \mathrm{ml}$ ) for the applied IFN- $\lambda 1 / 3$ ELISA. Furthermore, differences in SLE activity and medication at the time of blood sampling could affect the results. The current study, however, consisted mostly of patients with low disease activity and no drug effect was evident. Despite these limitations, we believe that the collective data presented in this study identify one likely mechanism for type III IFN induction in SLE.

\section{Conclusions}

In conclusion, we have shown that RNA-ICs activate a subset of pDCs to type III IFN synthesis and that this type III IFN production is promoted by other immune cells and several cytokines. We have also shown that targeting the TLR-MyD88 pathway inhibits the type III IFN production. As emerging data suggests that increased production of type III IFN is important in the SLE disease process, we propose that this IFN needs to be considered when developing drugs aiming to block or modulate the IFN system in SLE.

\section{Supplementary information}

Supplementary information accompanies this paper at https://doi.org/10. 1186/s13075-020-02186-Z.

Additional file 1: Figure S1. Interferon (IFN)- $\lambda 2$ displays cross reactivity in immunoassays of Interferon (IFN)- $\lambda 1 / 3$, but not IFN-a.

Additional file 2: Methods. Gene expression microarray. Single-cell RNA expression profiling

Additional file 3: Table S1. Clinical characteristics of SLE patients and their treatment at the time of blood sampling.

Additional file 4: Figure S2. Type III IFN production is induced in pDCs and $\mathrm{pDC}-\mathrm{B}$ cell co-cultures stimulated with RNA containing immune complexes (RNA-IC).

Additional file 5: Figure S3. Type I IFN production is induced in pDCs and PDC-NK or pDC-B cell co-cultures stimulated with RNA-IC.

Additional file 6: Figure S4. Interleukin (IL)-3, IL-6, GM-CSF and interferon (IFN) - a increase type I IFN production by pDCs stimulated with RNA-IC.

Additional file 7: Table S2. Differentially expressed genes (DEGs) in RNA-IC stimulated pDCs overexpressed in cluster " 1 " vs cluster "0". 54 top overexpressed genes in cluster "1" compared to cluster " 0 ".

Additional file 8: Table S3. Differentially expressed genes (DEGs) in RNA-IC stimulated pDCs overexpressed in cluster " 0 " vs cluster " 1 " following unsupervised clustering of the 2000 most variable genes.

Additional file 9: Figure S5. Interferon (IFN)-a production is triggered by RNA containing immune complexes (RNA-IC) in immune cells from systemic lupus erythematosus patients (SLE) patients and healthy controls.

\section{Abbreviations}

BDCA: Blood dendritic cell antigen; CCL: C-C motif chemokine ligand; CD: Cluster of differentiation; DELFIA: Dissociation-enhanced lanthanide fluorescence immunoassay; FcyRIIA: Fragment crystallizable receptor IIA; FDR: False discovery rate; FITC: Fluorescein isothiocyanate; GMCSF: Granulocyte-macrophage colony-stimulating factor;

HCQ: Hydroxychloroquine; IC: Immune complex; IFN: Interferon; IFNA2: Interferon alpha 2; Ig: Immunoglobulin; IL: Interleukin;

IRAK: Interleukin-1 receptor-associated kinase; IRAK4i: IRAK4 inhibitor; IRF: Interferon regulatory factor; ISGF: Interferon-stimulated gene factor; mAb: Monoclonal antibody; MIP: Macrophage inflammatory protein; MyD88: Myeloid differentiation primary response protein 88; NK: Natural killer; PBMC: Peripheral blood mononuclear cell; pDC: Plasmacytoid dendritic cell; RNA-IC: Ribonucleic acid containing immune complex; RNP: Ribonucleoprotein; SLE: Systemic lupus erythematosus; Sm: Smith nuclear antigen; snRNP: Small nuclear ribonucleoprotein; STAT: Signal transducer and activator of transcription; TLR: Toll-like receptor; TNF: Tumor necrosis factor

\section{Acknowledgements}

We thank Olof Berggren for the skillful cell preparation for microarray analysis, Lisbeth Fuxler and Cane Amcoff for the excellent technical assistance, and Rezvan Kiani Dehkordi for collecting the patient blood samples. We thank Dr. Gert Weber, Ernst-Moritz-Arndt University of Greifswald, for kindly providing the U1snRNP particles, and the SNP\&SEQ 
Technology Platform, Science for Life Laboratory, Uppsala Biomedical Centre, $B M C$, for single-cell sequencing.

\section{Authors' contributions}

Study design: $\mathrm{KH}, \mathrm{MLE}, \mathrm{LR}$. Laboratory data acquisition: $\mathrm{KH}, \mathrm{NH}$, MLE. Data analysis and interpretation: $\mathrm{KH}, \mathrm{NH}, \mathrm{PP}, \mathrm{MLE}$, LR. Draft writing: $\mathrm{KH}, \mathrm{NH}, \mathrm{PP}$, MLE, LR. Final revision: KH, NH, MLE, PP, LR. The authors read and approved the final manuscript.

\section{Funding}

The study was supported by The Swedish Rheumatism Association, King Gustaf V's 80-years Foundation, Agnes and Mac Rudberg's Foundation, AstraZeneca Science for Life Research Collaboration grant (DISSECT), The Swedish Research Council, and the Swedish Society of Medicine (the Ingegerd Johansson donation). The funding bodies had no role in any aspect of the study design, analysis, interpretation, or manuscript writing.

Open access funding provided by Uppsala University.

\section{Availability of data and materials}

The gene expression microarray datasets and the processed single-cell RNA seq data are available in Gene Expression Omnibus (GEO) (accession number GSE149456). The single-cell RNA seq raw data are available upon request from the authors on a collaborative basis and will be made available through a central repository when data safety regulations permit. All other data analyzed during this study are included in this published article and its supplementary information files.

\section{Ethics approval and consent to participate}

The local ethical committee of Uppsala approved the study, and informed consent was obtained from all participants.

\section{Consent for publication}

Not applicable.

\section{Competing interests}

$L R$ received a research grant from AstraZeneca. The remaining authors declare that they have no competing interests.

\section{Received: 10 February 2020 Accepted: 14 April 2020 Published online: 05 June 2020}

\section{References}

1. Crow MK. Type I interferon in the pathogenesis of lupus. J Immunol (Baltimore, Md : 1950). 2014;192(12):5459-68

2. Hagberg N, Ronnblom L. Systemic lupus erythematosus--a disease with a dysregulated type I interferon system. Scand J Immunol. 2015;82(3):199-207.

3. Baechler EC, Batliwalla FM, Karypis G, Gaffney PM, Ortmann WA, Espe KJ et al. Interferon-inducible gene expression signature in peripheral blood cells of patients with severe lupus. Proc Natl Acad Sci U S A. 2003;100(5): 2610-5.

4. Bengtsson AA, Ronnblom L. Role of interferons in SLE. Best Pract Res Clin Rheumatol. 2017;31(3):415-28.

5. Ronnblom L, Leonard D. Interferon pathway in SLE: one key to unlocking the mystery of the disease. Lupus Sci Med. 2019;6(1):e000270.

6. Oke V, Brauner S, Larsson A, Gustafsson J, Zickert A, Gunnarsson I, et al. IFNlambda1 with Th17 axis cytokines and IFN-alpha define different subsets in systemic lupus erythematosus (SLE). Arthritis Res Ther. 2017;19(1):139.

7. Kotenko SV, Gallagher G, Baurin W, Lewis-Antes A, Shen M, Shah NK, et al. IFN-lambdas mediate antiviral protection through a distinct class II cytokine receptor complex. Nat Immunol. 2003;4(1):69-77.

8. Sommereyns C, Paul S, Staeheli P, Michiels T. IFN-lambda (IFN-lambda) is expressed in a tissue-dependent fashion and primarily acts on epithelial cells in vivo. PLoS Pathogens. 2008;4(3):e1000017. https://doi.org/10.1371/ journal.ppat.1000017.PMID:18369468).

9. Lin FC, Young HA. Interferons: success in anti-viral immunotherapy. Cytokine Growth Factor Rev. 2014;25(4):369-76.

10. Lazear HM, Nice TJ, Diamond MS. Interferon-lambda: immune functions at barrier surfaces and beyond. Immunity. 2015;43(1):15-28.

11. Zhou Z, Hamming OJ, Ank N, Paludan SR, Nielsen AL, Hartmann R. Type III interferon (IFN) induces a type I IFN-like response in a restricted subset of cells through signaling pathways involving both the Jak-STAT pathway and the mitogen-activated protein kinases. J Virol. 2007:81(14):7749-58.

12. Hertzog P, Forster S, Samarajiwa S. Systems biology of interferon responses. Interf Cytokine Res. 2011:31(1):5-11.

13. Andreakos E, Zanoni I, Galani IE. Lambda interferons come to light: dual function cytokines mediating antiviral immunity and damage control. Curr Opin Immunol. 2018;56:67-75.

14. Kotenko SV, Rivera A, Parker D, Durbin JE. Type III IFNs: beyond antiviral protection. Semin Immunol. 2019;43:101303.

15. Yin Z, Dai J, Deng J, Sheikh F, Natalia M, Shih T, et al. Type III IFNs are produced by and stimulate human plasmacytoid dendritic cells. J Immunol (Baltimore, Md : 1950). 2012;189(6):2735-45.

16. Rönnblom L, Alm GV. The natural interferon-alpha producing cells in systemic lupus erythematosus. Hum Immunol. 2002;63(12):1181-93.

17. Della Chiesa M, Romagnani C, Thiel A, Moretta L, Moretta A. Multidirectional interactions are bridging human NK cells with plasmacytoid and monocytederived dendritic cells during innate immune responses. Blood. 2006; 108(12):3851-8

18. Eloranta ML, Lovgren T, Finke D, Mathsson L, Ronnelid J, Kastner B, et al. Regulation of the interferon-alpha production induced by RNA-containing immune complexes in plasmacytoid dendritic cells. Arthritis Rheum. 2009; 60(8):2418-27.

19. Hagberg N, Berggren O, Leonard D, Weber G, Bryceson YT, Alm GV, et al. IFN-alpha production by plasmacytoid dendritic cells stimulated with RNAcontaining immune complexes is promoted by NK cells via MIP-1beta and LFA-1. J Immunol. 2011;186(9):5085-94.

20. Berggren O, Hagberg N, Weber G, Alm GV, Ronnblom L, Eloranta ML. B lymphocytes enhance interferon-alpha production by plasmacytoid dendritic cells. Arthritis Rheum. 2012;64(10):3409-19.

21. Leonard D, Eloranta ML, Hagberg N, Berggren O, Tandre K, Alm G, et al. Activated $T$ cells enhance interferon-alpha production by plasmacytoid dendritic cells stimulated with RNA-containing immune complexes. Ann Rheum Dis. 2016;75(9):1728-34.

22. Lovgren T, Eloranta ML, Kastner B, Wahren-Herlenius M, Alm GV, Ronnblom $\mathrm{L}$. Induction of interferon-alpha by immune complexes or liposomes containing systemic lupus erythematosus autoantigen- and Sjogren's syndrome autoantigen-associated RNA. Arthritis Rheum. 2006;54(6):1917-27.

23. Shafaie $S$, Hutter $V$, Brown MB, Cook MT, Chau DYS. Influence of surface geometry on the culture of human cell lines: a comparative study using flat, round-bottom and v-shaped 96 well plates. PLoS One. 2017;12(10): e0186799.

24. Weber G, Trowitzsch S, Kastner B, Luhrmann R, Wahl MC. Functional organization of the Sm core in the crystal structure of human U1 snRNP. EMBO J. 2010;29(24):4172-84.

25. Bach M, Krol A, Luhrmann R. Structure-probing of U1 snRNPs gradually depleted of the U1-specific proteins A, C and 70k. Evidence that A interacts differentially with developmentally regulated mouse U1 snRNA variants. Nucleic Acids Res. 1990;18(3):449-57.

26. Kastner B, Bach M, Luhrmann R. Electron microscopy of small nuclear ribonucleoprotein (snRNP) particles U2 and U5: evidence for a common structure-determining principle in the major U snRNP family. Proc Natl Acad Sci U S A. 1990;87(5):1710-4.

27. Kelly PN, Romero DL, Yang Y, Shaffer AL 3rd, Chaudhary D, Robinson S, et al. Selective interleukin-1 receptor-associated kinase 4 inhibitors for the treatment of autoimmune disorders and lymphoid malignancy. J Exp Med. 2015;212(13):2189-201.

28. Hjorton K, Hagberg N, Israelsson E, Jinton L, Berggren O, Sandling JK, et al. Cytokine production by activated plasmacytoid dendritic cells and natural killer cells is suppressed by an IRAK4 inhibitor. Arthritis Res Ther. 2018;20(1):238.

29. Cederblad B, Blomberg S, Vallin H, Perers A, Alm GV, Ronnblom L. Patients with systemic lupus erythematosus have reduced numbers of circulating natural interferon-alpha- producing cells. J Autoimmun. 1998;11(5):465-70.

30. Khan S, Kaihara KA. Single-cell RNA-sequencing of peripheral blood mononuclear cells with ddSEQ. Methods Mol Biol. 1979:2019:155-76.

31. Tan EM, Cohen AS, Fries JF, Masi AT, McShane DJ, Rothfield NF, et al. The 1982 revised criteria for the classification of systemic lupus erythematosus. Arthritis Rheum. 1982;25(11):1271-7.

32. Gladman DD, Ibanez D, Urowitz MB. Systemic lupus erythematosus disease activity index 2000. J Rheumatol. 2002;29(2):288-91.

33. Fitzgerald-Bocarsly P. Natural interferon-alpha producing cells: the plasmacytoid dendritic cells. Biotechniques. 2002;Suppl:16-20, 2, 4-9. 
34. Lovgren T, Eloranta ML, Bave U, Alm GV, Ronnblom L. Induction of interferon-alpha production in plasmacytoid dendritic cells by immune complexes containing nucleic acid released by necrotic or late apoptotic cells and lupus IgG. Arthritis Rheum. 2004;50(6):1861-72.

35. Bengtsson AA, Sturfelt G, Truedsson L, Blomberg J, Alm G, Vallin H, et al. Activation of type I interferon system in systemic lupus erythematosus correlates with disease activity but not with antiretroviral antibodies. Lupus. 2000;9(9):664-71.

36. Fiehn C, Wermann M, Pezzutto A, Hufner M, Heilig B. Plasma GM-CSF concentrations in rheumatoid arthritis, systemic lupus erythematosus and spondyloarthropathy. Z Rheumatol. 1992;51 (3):121-6.

37. Willeke P, Schluter B, Schotte H, Erren M, Mickholz E, Domschke W, et al. Increased frequency of GM-CSF secreting PBMC in patients with active systemic lupus erythematosus can be reduced by immunoadsorption. Lupus. 2004;13(4):257-62.

38. Tang Y, Tao H, Gong Y, Chen F, Li C, Yang X. Changes of serum IL-6, IL-17, and complements in systemic lupus erythematosus patients. J Interf Cytokine Res. 2019;39(7):410-5.

39. Iwano M, Dohi K, Hirata E, Kurumatani N, Horii Y, Shiiki H, et al. Urinary levels of IL-6 in patients with active lupus nephritis. Clin Nephrol. 1993;40(1): $16-21$.

40. Fishman P, Kamashta M, Ehrenfeld M, Vianna J, Hughes GR, Sredni D, et al. Interleukin-3 immunoassay in systemic lupus erythematosus patients: preliminary data. Int Arch Allergy Immunol. 1993;100(3):215-8.

41. Renner K, Hermann FJ, Schmidbauer K, Talke Y, Rodriguez Gomez M, Schiechl G, et al. IL-3 contributes to development of lupus nephritis in MRL/ Ipr mice. Kidney Int. 2015;88(5):1088-98.

42. Oon S, Monaghan K, Ng M, Hoi A, Morand E, Vairo G, et al. A potential association between IL-3 and type I and III interferons in systemic lupus erythematosus. Clin Transl Immunology. 2019;8(12):e01097.

43. Zickert A, Oke V, Parodis I, Svenungsson E, Sundstrom Y, Gunnarsson I. Interferon (IFN)-lambda is a potential mediator in lupus nephritis. Lupus Sci Med. 2016:3(1):e000170.

44. Rose T, Dorner T. Drivers of the immunopathogenesis in systemic lupus erythematosus. Best Pract Res Clin Rheumatol. 2017;31(3):321-33.

45. Berggren O, Alexsson A, Morris DL, Tandre K, Weber G, Vyse TJ, et al. IFNalpha production by plasmacytoid dendritic cell associations with polymorphisms in gene loci related to autoimmune and inflammatory diseases. Hum Mol Genet. 2015;24(12):3571-81.

46. Morand EF, Furie R, Tanaka Y, Bruce IN, Askanase AD, Richez C, et al. Trial of anifrolumab in active systemic lupus erythematosus. N Engl J Med. 2020; 382(3):211-21.

47. Zahn S, Rehkämper C, Kümmerer BM, Ferring-Schmidt S, Bieber T, Tüting T, et al. Evidence for a pathophysiological role of keratinocyte-derived type III interferon (IFN $\lambda$ in cutaneous lupus erythematosus. J Investigative Dermatol. 2011:131(1):133-40

48. Wu et al.: Interferon-lambda1 induces peripheral blood mononuclear cellderived chemokines secretion in patients with systemic lupus erythematosus: its correlation with disease activity. Arthritis Res Ther. 2011;13:R8.

49. Chen JY, Wang CM, Chen TD, Jan Wu YJ, Lin JC, Lu LY, et al. Interferonlambda3/4 genetic variants and interferon-lambda3 serum levels are biomarkers of lupus nephritis and disease activity in Taiwanese. Arthritis Res Ther. 2018;20(1):193.

50. Amezcua-Guerra LM, Marquez-Velasco R, Chavez-Rueda AK, Castillo-Martinez D, Masso F, Paez A, et al. Type III interferons in systemic lupus erythematosus: association between interferon lambda3, disease activity, and anti-Ro/SSA antibodies. J Clin Rheumatol. 2017:23(7):368-75.

51. Macal M, Jo Y, Dallari S, Chang AY, Dai J, Swaminathan S, et al. Self-renewal and toll-like receptor signaling sustain exhausted plasmacytoid dendritic cells during chronic viral infection. Immunity. 2018;48(4):730-44 e5.

52. Blomberg S, Eloranta ML, Cederblad B, Nordlin K, Alm GV, Ronnblom L. Presence of cutaneous interferon-alpha producing cells in patients with systemic lupus erythematosus. Lupus. 2001;10(7):484-90.

\section{Publisher's Note}

Springer Nature remains neutral with regard to jurisdictional claims in published maps and institutional affiliations.

\section{Ready to submit your research? Choose BMC and benefit from}

- fast, convenient online submission

- thorough peer review by experienced researchers in your field

- rapid publication on acceptance

- support for research data, including large and complex data types

- gold Open Access which fosters wider collaboration and increased citations

- maximum visibility for your research: over $100 \mathrm{M}$ website views per year

At $\mathrm{BMC}$, research is always in progress.

Learn more biomedcentral.com/submissions 